\title{
Assessment of Radiographic Image Quality by Visual Examination of Neutron Radiographs of the Calibration Fuel Pin
}

Domanus, Joseph Czeslaw

Publication date:

1986

Document Version

Publisher's PDF, also known as Version of record

Link back to DTU Orbit

Citation (APA):

Domanus, J. C. (1986). Assessment of Radiographic Image Quality by Visual Examination of Neutron Radiographs of the Calibration Fuel Pin. Risø National Laboratory. Risø-M No. 2578

\section{General rights}

Copyright and moral rights for the publications made accessible in the public portal are retained by the authors and/or other copyright owners and it is a condition of accessing publications that users recognise and abide by the legal requirements associated with these rights.

- Users may download and print one copy of any publication from the public portal for the purpose of private study or research.

- You may not further distribute the material or use it for any profit-making activity or commercial gain

- You may freely distribute the URL identifying the publication in the public portal

If you believe that this document breaches copyright please contact us providing details, and we will remove access to the work immediately and investigate your claim. 
RISE-M-2578

ASSESSMENT OF RADIOGRAPHIC IMAGE QUALITY BY VISUAL EXAMINATION OF NEUTRON RADIOGRAPHS OF THE CALIBRATION FUEL PIN

J. C. Domanus

Abstract. Up till now no reliable radiographic image quality standards exist for neutron radiography of nuclear reactor fuel. Under the Euratom Neutron Radiography Working Group (NRWG) Test Program neutron radiographs were produced at different neutron radiography facilities within the European Community of a calibration fuel pin.

The radiographs were made by the direct, transfer and tracketch methods using different film recording materials. These neutron radiographs of the calibration fuel pin were used for the assessement of radiographic image quality. This was done by visual examination of the radiographs and assessing their radiographic image quality on an arbitrary scale.

INIS Desciptors: CALIBRATION; FUEL PINS; IMAGES; NEUTRON RADIOGRAPHY; PHOTOGRAPHIC EILMS; QUALITY CONTROL; STANDARDIZATION.

Accepted for presentation at the second world Conference on Neutron Radiography, Par18, 16-20.06.1986.

Apr 111986

Riso National Laboratory, DK-4000 Roskilde, Denmark 
ISBN $87-550-1221-1$

ISSN 0418-6435

Grafisk Service, Risø 1986 
CORTEIrS

Page

1. IRTRODOCTION $\ldots \ldots \ldots \ldots \ldots \ldots \ldots \ldots \ldots \ldots \ldots \ldots \ldots \ldots \ldots \ldots . \ldots$

2. VISUAL EXAMINATION OF MEUTRON RADIOGRAPHS ........ 6

3. EVALUATION OR EXAMIMATION RESULTS $\ldots \ldots \ldots \ldots \ldots \ldots \ldots \ldots$ 7

3.1. General evaluation .................... 7

3.2. Silver halide vs. nitrocellulose filn ......... g

3.3. Track-etch method with nitrocellulose film ..... 9

4. Concwusions $\ldots \ldots \ldots \ldots \ldots \ldots \ldots \ldots \ldots \ldots \ldots \ldots \ldots \ldots \ldots \ldots \ldots$

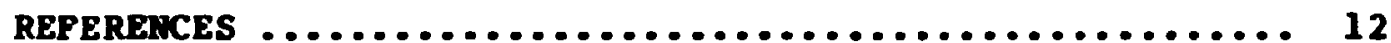





\section{INTRODUCTION}

Up till now only one standard was published in which the problem of determining image quality of neutron radiographs is discussed. It is the ASTM E545-81 III. In both the first issue of the E545 from 1975 as well as in the issue of 1981 the method was 1 imited to neutron radiography performed with metallic converter screens and silver halide film. Therefore, it could be used for the assessment of radiographic image quality of irradiated nuclear fuel (radiography performed with the transfer method using, e.g. Dy converter and $X$-ray film).

This E545 standard is now under revision and in the 1985 draft $|2|$ it is now limited to the direct method and single emulsion silver halide film. It is therefore not suitable for neutron radiography of irradiated nuclear fuel, where either the transfer method and silver halide film or nitrocellulose film are used.

The need for a separate method of assessment of the radiographic image quality in neutron radiography of nuclear fuel was recognised long ago. Already in 1976 a calibration fuel pin was designed and produced at Riso. It was used to check the accuracy of dimensional measurements from neutron radiographs $|3|$.

This calibration fuel pin was thereafter used at Riso for the visual comparison of image quality of nuclear fuel neutron radiographs $|4|$. It was also used for the assessemnt of the nitrocellulose film $|5|$ by the visual method.

When the Euratom Neutron Radiography Working Group (NRWG) was constituted in 1979 a new design of the calibration fuel pin $16 \mid$ was adapted and is now used in the NRWG Test Program $17 \mathrm{l}$.

The control of radiographic image quality in neutron radiography of nuclear fuel was also discussed in $|8,9,10|$. 
Under the NRWG Test Program the sensitivity level is visually evaluated from neutron radiographs of the sensitivity indicator SI, as prescribed by the ASTM E545.

The conclusions from this visual examination were already drawn in $|8|$ and thereafter were formulated in $|9|$ as follows: "The assessment of radiographic image quality by the evaluation of the components of the $S I$ is not selective enough if the visible gaps are counted (all are always seen). At the same time it gives an incorrect impression of image quality from the evaluation of visible holes leven with good $L / D$ more than 4 holes can be seen very rarely).

Similar conclusions were drawn by A. Laporte and G. Bayon from their investigation described in $|11|$.

Since the ASTM method of determining the sensitivity level from the visual examination is not selective enough another approach was adopted at Riso to determine the radiographic image quality.

\section{VISUAL EXAMINATION OF NEUTRON RADICGRAPHS}

Under the NRWG Test Progam neutron radiographs of the calibration fuel pun CFP-El were made using different $\mathrm{film} /$ converter combinations (as described in $|7|$ and $|12|$ where the NRWG Test Program markings are shown). Those radiographs were thereafter visually examined.

The quality of the radiographic image of the CPP-El can be best assessed by judging the sharpness of the pellet-to-clad calibrated gaps by eye. Due to the geometry of the test object (calibration fuel pin - rund object) it is very difficult to get a sharp image of the small gaps on a radiograph. The sharpest radiographic image of the gaps of the calibration fuel pin could be obtained by $x$-rays. Therefore an $x$-ray radiograph (taken at $140 \mathrm{kV}$ ) was used as reference for assessing image quality on neutron radiographs. 
An arbitary scale was used (from 1 to 5 ) where the sharpest picture produced by $x$-rays was given the value of 5 . Three persons were visually examining the neutron radiographs of the CFP-El and were assessing the image quality of those radiographs by using the 1 to 5 arbitrary scale.

The results of this examination are summarized in fig. 1. Here the assessment of each of the three persons is marked by a black line. The dotted markings on fig. 1 mean, that the findings of all three persons were the same. In further evaluation of the above results only those dotted findings were taken into consideration.

The method used in this investigation proves to be useful as it shows differences in quality for neutron radiographs obtained by different methods using different recording material. At the same time in can differentiate between neutron radiographs taken by the same method on the same recording material but at different neutron facilities with different $L / D$ ratios.

\section{EVALUATION OP EXAMINATION RESULTS}

The results of the visual examination, summarized in fig. 1 can be used for different comparisons of the radiographic image quality of neutron radiographs of the CFP-El taken by various exposure and recording techniques.

\subsection{General eyaluation}

If one will look for the best results obtained among all techniques and recording materials one will see that for each NR facility best radiographic quality was always reached by the direct method using a single-coated, fine grain, silver halide film and $25 \mathrm{~m}$ Gd converter.

This is quite obvious and could be expected in advance. In those facilities (MOl BR2, Petten $\mathrm{BB} 8$ and PO), where the direct 


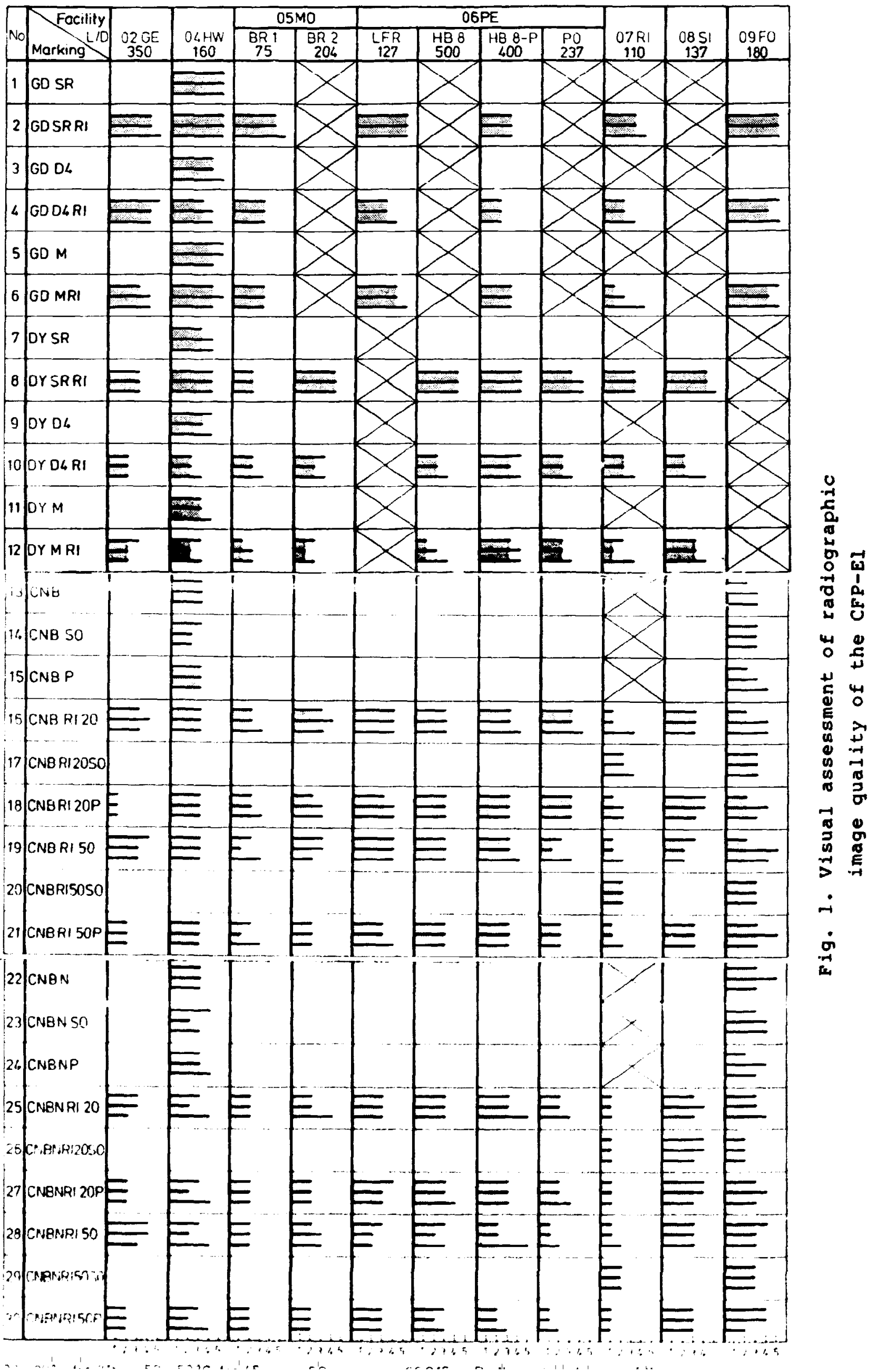


method could not be used, best radiographic image quality was reached by using the fine grain, single-coated silver halidc film for the transfer method using a $100 \mu \mathrm{m}$ Dy converter.

As such general comparison of all exposure techniques and recording materials is meaningless, below other comparisons were made of methods and recorders which can be used optionally for specific applications (radioactive or non-radioactive objects).

\subsection{Silver halide vse aitrocellulose film}

When examining radioactive objects (e.g. spent nuclear fuel) either the direct method with silver halide film or the tracketch method with nitrocellulose film can be used. Therefore those two methods will be compared now.

While looking on the results, listed on fig. 1 under numbers 7 to 12 (for the direct method with a $100 \mu m$ Dy converter) and numbers 13 to 30 (for the track etch method) one can do such a comparison.

Here the best radiographic image quality was reached for the transfer method with the Dy converter using a single coated, fine grain silver halide $f i l m$.

The results reached in the comparison of the silver halide and nitrocellulose film were analyzed in detail in $|13|$.

Looking again on fig. l one can see, that for some NR facilities equally good results were reached with the direct method using either a single coated as well as a double-coated silver hallde film.

\subsection{Track-etch method with nitrocellulose film}

It will be interesting not only to compare the transfer with the 
track-etch method but also to look closer into the different recording and evaluating methods possible with the nitrocellulose film.

Here two possibilities are open. One can use a double coated

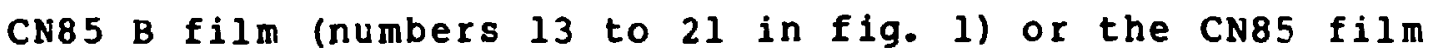
sandwiched between two BNl converters (numbers 22 to 30 in $\mathrm{fig}$. 1).

Both combinations can be viewed either directly (numbers 13, 16, 19, for CN85B and 22, 25, 28 for CNB + BN1), viewed from copies on high contrast duplicating film (numbers 14, 17,20 for CN85B and 23, 26, 29 for CN85 + BN1), or viewed through polarizing filters (numbers 1, 18, 21 for CN85B and 24, 27, 30 for CN85+ BN1).

\subsubsection{Direct viewing}

It usually gives the same results of radiographic image quality whether judged from the double-coated CN85B of the CN85 film used with two BNl converters.

\subsubsection{Viewing from copies}

On high contrast silver halide film it can sometimes improve the radiographic image quality. However, the main advantage of using such copies is their easier interpretation, as they look like neutron radiographs taken on silver halide $f 11 \mathrm{~m}$.

\subsubsection{Viewing through polarizing filters}

This technique is used for the same purpose as the former, i.e. to facilitate viewing. Also here the neutron radiographs on nitrocellulose film appear as those on silver hallde film.

In most instances the radiographic image quality was equally good when viewed through polarizing filters as viewed directly without them. 


\subsubsection{Etching conditions}

Neutron radiographs taken at different NR facilities were thereafter etched at Risø both at $200 \mathrm{C}$ for $21 \mathrm{~h}$ (number 16 for CN85B and 25 for CN85 + BN1) and $50^{\circ} \mathrm{C}$ for $45 \mathrm{~min}$ (number 19 for CN85B and 28 for CN85 + BN1). Here only in few instances the $200 \mathrm{C}, 21 \mathrm{~h}$ etching gave siightly

better image quality results than the $500 \mathrm{C}, 45 \mathrm{~min}$. procedure.

\subsubsection{Influence of the $1 / D$ ratio}

The last factor which could be studied from the results summarized in fig. 1 was the influence of the $L / D$ ratio on the radiographic image quality.

The L/D ratios of NR facilities used in the NRWG Test Program varied from 75 to 500 .

Here no direct connection between the $L / D$ ratio and the radiographic image quality could be found. It is probably due to the fact that the $L / D$ radio itself is not the only decisive factor in that respect. Other factors, as e.g. the gamma ray content in the neutron beam have also influence on the overall radiographic image quality.

\section{CONCLUSIONS}

After analyzing the partial results of the NRWG Test Program (summarized in fig. 1) one can come to a general conclusion that for such different NR facilities as listed in fig. 1 (with different L/D ratios, different gamma-ray content in the neutron beam and different exposure geometries) recommendations as to the use of a best exposure and recording technique can be given only whe analyzing the results reached for each particular facility. 
However, many interesting general informations about the radiographic image quality can be found in the comparison performed in chapter 3 above.

It must be stressed that the analysis performed in this paper has taken into account only the subjective evaluation of radiographic image quality by the visual examination of neutron radiograph of a calibration fuel pin. In this analysis such factors as the relative speed of different exposure and recording methods were not taken into account. They can, however, be the decisive factors for some applications.

The problem of accuracy of dimensional measurments from neutron radiographs was also outside of the scope of this analysis. This problem was taken into account in $|13|$ when comparing the properties of silver halide and nitrocellulose film.

\section{REFERENCES}

III ASTM E545-81. Standard method for determining image quality in thermal neutron radiographic testing.

121 ASTM Draft E545-85. Standard method for determinirg image quality in direct thermal neutron radiographic testing.

$|3|$ DOMANus J. C., Accuracy of dimension measurements from neutron radiographs of nuclear fuel pins. Risø-M-1860. 26.03.1976 (also as paper 348 presented at the Eighth World Conference on Nondestructive Testing, Cannes, 611.09 .1976 .

I 4 DOMANUS, J. C., Comparison of image quality of nuclear fuel neutron radiographs taken on silver halide and nitrocellulose film. Riso-M-2170, April 1979 (also as paper 2BDD-1 of the Ninth World Conference on Non-Destructive Testing, Melbourne, 18-23.11.1979). 
I5I J. C. Domanus. How good is the nitrocellulose film for neutron radiography? 729-736 in the Proceedings of le 1 st WCNR.

161 J. C. Domanus. Calibration fuel pin CFP-El. Risø Report B499. Metallurgy Department, Risø National Laboratory. February 1981.

I7| J. C. Domanus. Euratom test program for image quality and accuracy of dimensions. 1025-1033 in Proceedings of the lst WCNR.

$|8|$ J. C. Domanus. Control of radiographic image quality in neutron radiography of nuclear fuel. Proceedings of the 6 th ASM International Conference on NDE in the Nuclear Industry. Ztrich, Switzerland. 28.11.-2.12.1983, 447-451.

$|9|$ J. C. Domanus, P. Gade-Nielsen \& J. Olsen. How good are the standards for the image quality control in neutron radiography of nuclear fuel? Proceedings of the $7 \mathrm{th}$ international conference on NDE in the Nuclear Industry. Grenoble, France. 29.1-1.2.1985. 325-328.

$|10|$ J. C. Domanus. Activities and achievements of the Euratom Radiography Working Group. Materials Evaluation, Vol. 44, No 1 , January 2986 , 114-119.

111 A. Laporte G. Bayon. Determination of image quality in industrial neutron radiography. CEN-FAR. Service des Piles de Saclay - Section d'exploatation TRITON. 6.203.2.

$112 \mid$ J. C. Domanus. Euratom Neutron Radiography Working Group. Proceedings of the 2nd WCNR.

$113 \mid$ J. C. Domanus. In "Neutron radiography on nitrocellulose film". EUR report to be published in 1986. 
ASSESSMENT OF RADIOGRAPHIC IMAGE QUALITY BY VISUAL EXAMINATION OF NEUTRON RADIOGRAPHS OF THE CALIBRATION FUEL PIN

J. C. Domanus

$$
\text { If } 9 \text { pages }+ \text { tables }+1 \text { illustraticns }
$$

Abstract

Up till now no reliable radiographic quality standards exist for neutron radiography of nuclear reactor fuel. Under the Euratom Neutron Radiography Working Group (NRWG) Test Program neutron radiographs were produced at different neutron radiography facilities within the European Community of a calibration fuel pin.

The radiographs were made by the direct, transfer and track-etch methods using different film recording materials. Those neutron radiographs of the calibration fuel pin were used for the assessment of radiographic image quality. This was done by visual examination of the radiographs and assessing their radiographic image quality on an arbitrary scale.

Accepted for presentation at the Second World Conference on Neutron Radiography, Paris, $16-20.06 .1986$.

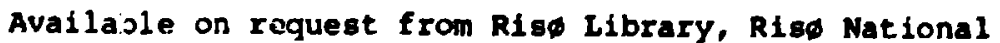
Laboratory (Risø Bibliotek), Forsegsanlag Risф), DK-4000 Roskilde, Denmark

Telephone: (02) 371212 , ext. 2262. Telex: 43116 